\title{
Bir Üniversite Hastanesine Gebelikte İlaç Kullanımı İçin Başvuran Gebelerin Değerlendirilmesi: Bir Olgu Serisi
}

\author{
Evaluation of Pregnant Women Who Applied to A University Hospital For Drug Use \\ During Pregnancy: A Case Series
}

\section{Kemal Gökhan Ulusoy}

Sağllk Bilimleri Üniversitesi, Gülhane Tip Fakültesi Tibbi Farmakoloji Anabilim Dalı, Etlik, ANKARA

\author{
Yazısma Adresi / Correspondence: \\ Kemal Gökhan Ulusoy
}

Sağlık Bilimleri Üniversitesi, Gülhane Tip Fakültesi Tibbi Farmakoloji Anabilim Dalı,

General Dr. Tevfik Sağlam Caddesi 06018 Etlik, Keçiören ANKARA

T: +905336635785 E-mail : kemalgokhan.ulusoy@sbu.edu.tr

Geliş Tarihi / Received : 01.07.2020 Kabul Tarihi / Accepted : 02.09.2020

Orcid :

Kemal Gökhan Ulusoy https://orcid.org/ 0000-0003-1786-2945

(Sakarya Tip Dergisi / Sakarya Med J 2020, 10(3):459-466) DOI: 10.31832/smj.762086

Ö

Amaç Gebelikte ilaç kullanımı hem anne hem de fetüs için olumsuz etkiler olușturabilir. İlaç kullanımına bağlı teratojenite risk değerlendirmesi bu etkileri azaltmak için önemlidir. Bu çalışmada amacımız kliniğimize başvuran gebelerde en sık kullanılan ilaçları ve bunlara ait güncel bilgileri değerlendirmektir.

Gereçve Bu çalıșmada 1 Ocak 2011- 31 Aralık 2016 tarihleri arasında Tibbi Farmakoloji Anabilim dalına ilaç kullanım öyküsüyle bașvuran gebeler retrospektif olarak

Yöntem değerlendirilmiștir. Tüm gebelerin bir kadın hastalıkları ve doğum uzmanın tarafından gebeliği tıbbi olarak kanıtlanmıştır. Gebelikte kullanılan ilaçlar 'Anatomic Therapeutic Chemical' (ATC) sınıflandırılması kodlarına göre sınıflandırılmış, risk kategorisi olarak Amerika Birleșik Devletleri’nin Gıda ve İlaç Dairesi ( FDA ) kategorileri kullanılmıștır.

Bulgular Calıșmada 109 gebe değerlendirilmiștir. Gebelerin ortalama yașı 32 olup, \%37,61'i 30-34 yas aralığındadır. Gebelik sırasında en sık kullanılan ilaçlar kemoterapötikler $(\% 13,02)$, antiinflamatuvar ve romatizmal ilaçlar $(\% 12,67)$, solunum sistemi ilaçları $(\% 8,80)$, seks hormonları ve modülatörleri $(\% 8,45)$ ve gastrointestinal sistem ilaçlarıdır $(\% 7,04)$. FDA kategorilerine göre ise kullanılan ilaçların \%49,3'ü 'C' kategorisinde, $\% 22,5$ ' i 'B' kategorisinde, $\% 14,4$ 'u ' $X$ ' kategorisinde, \%10,2'si ' $\mathrm{D}$ ' kategorisinde ve $\% 3,5$ ' $\mathrm{i}$ 'A' kategorisinde yer almaktadır. Ayrıca gebelerin \%64’ü birden fazla ilaç kullanmış ve ortalama ilaç kullanım sayısı 2,60’dır.

Sonuç Gebeler teratojenite riski olan ilaçlara yüksek ortanda maruz kalabilmektedir ve gerek ilaç reçete eden hekimlerin, gerekse ilacı kullanan doğurganlık çağındaki kadınların, kullanım öncesi mutlaka gebelik durumunu sorgulaması gerekmektedir. Gebelik durumunda ise ilaç seçiminin mümkün olan en az risk taşıan gruptan yapılması önem arz etmektedir. Daha uygun bir risk değerlendirmesi için de mevcut sınıflandırma yeterli gözükmemektedir.

Anahtar gebelik; ilaç güvenliği; teratojenler; risk değerlendirmesi

Abstract

Objective Drug use in pregnancy can cause unfavorable effects on both mother and fetus. Drug use-related teratogenicity risk assessment is important to reduce these effects. In this study, our aim was to evaluate the most frequently used drugs and current information in pregnant women who applied to our clinic.

Metarials In this study, pregnant women who applied to the Department of Medical Pharmacology between January 1st, 2011 and December 31 st, 2016 were evaluated retrospectively. All pregnant and methods women have been medically proven their pregnancy by a gynecologist and obstetrician. Drugs used during pregnancy are classified according to 'Anatomic Therapeutic Chemical' (ATC) codes and the U.S.Food and Drug Administration (FDA) risk categories were used.

Results 109 pregnant women were evaluated in this study. The average age of pregnant women was 32, and $37.61 \%$ of them were between the ages of $30-34$. The most frequently used drugs during pregnancy were chemotherapeutics (13.02\%), anti-inflammatory and rheumatic drugs (12.67\%), respiratory system drugs (8.80\%), sex hormones and modulators (8.45\%) and gastrointestinal drugs ( $7.04 \%)$. According to FDA categories; $49.3 \%$ of the drugs used were in the ' $C$ ', $22.5 \%$ in the ' $B$ ', $14.4 \%$ in the ' $X$ ', $10.2 \%$ in the ' $D$ ' and $3.5 \%$ are in the 'A' categories. In addition, $64 \%$ of pregnant women used more than one drug and the average number of drugs used was 2.60 .

Conclusion Pregnant women can be exposed to drugs with a high risk of teratogenicity, and both physicians prescribing drugs and women of childbearing age who use the drug must interrogate the pregnancy status before use. In case of pregnancy, it is important to choose the drug from the minumum risky group as possible. The current classification also does not seem sufficient for a more appropriate risk assessment.

Keywords pregnancy; drug safety; teratogens; risk assessment 


\section{GIIRIș}

Gebelikte ilaç kullanımı hem gebe hem de fetüs üzerinde olumsuz etkiler oluşumuna neden olabilecek, fakat gerekli önemler alınarak riskin azaltılabileceği bir süreçtir. Günümüzde gebelerde ilaç kullanımı, sıklıkla gebenin hamile olduğunu bilmeden ilaç kullanması veya kronik kullanılan bir ilacın etkisi altındayken gebe kalması şeklinde karşımıza çıkmaktadır. Bunun yanı sıra gebelik sırasında ortaya çıkan hastalıklara yönelik tedavi ihtiyacı da ilaç kullanımını gerektirebilmektedir. Üstelik bu hastalıkların tedavisinin gerçekleştirilmemesi hem annenin hem de bebeğinin sağlığını olumsuz yönde etkileyebilir. ${ }^{1}$ Gebelikte ilaç kullanım sıklığı ülkeler arasında farklılıklar gösterebilse de farklı ülkelerde yapılan çalışmalar gebeliklerinde en az bir ilaç kullanan gebelerinin oranının \%60 ile \%81 arasında olabileceğini göstermektedir. ${ }^{2-4}$

İlaç etkinliği için yapılan klinik çalışmalardan elde edilen bilgiler teratojenite riski açısından yetersizdir. Gebelerde klinik çalışma yapma olanağı etik nedenlerden dolayı çok sınırlı olduğundan, birçok ilaç için sadece deney hayvanı çalışmaları ile elde edilen bilgiler mevcuttur. Zamanla bu ilaçların ruhsatlandırılıp kullanılmaya başlamasıyla gebelerde de kullanım mümkün olmakta, retrospektif çalışmalarla bu kullanımlarda oluşan risk artışı değerlendirilebilmektedir. Bunun yanı sıra birçok durumda, hamilelik sırasında ilaç tedavisi ile ilgili kararlar, tedavinin etkinliği ve güvenliği hakkında kanıta dayalı bilgi olmadan verilmektedir. Fetal gelişim için zararlı olduğu kesin olarak bilinen ilaçlar olmakla birlikte, fetüse zararın değerlendirilmesine ilişkin kanıtlar ilaçların çoğu için halen yeterli değildir.

Hamilelikte kullanılan ilaçlar fetüs üzerinde birçok farklı olumsuz etkilere neden olabilir. Konjenital anomaliler ile ilgili kaygı, hamilelik sırasında ebeveyn üzerinde önemli bir stres faktörü olabilmektedir. Amerikan Gıda ve İlaç Dairesi (FDA) tarafından geliştirilen (1979) ve günümüzde ilaç kısa ürün bilgisinde (KÜB) yer alması zorunlu olan gebelik risk kategorileri (Tablo.1) her ne kadar ilaçlar hak- kında bir fikir verse de risk değerlendirmesi açısından yeterli değildir.

\begin{tabular}{|l|l|}
\hline \multicolumn{2}{|l|}{$\begin{array}{l}\text { Tablo.1. İlaçların Risk Sınıflandırılmasında Kullanılan FDA* } \\
\text { Gebelik Kategorileri }\end{array}$} \\
\hline Kategori & Açıklama \\
\hline A & $\begin{array}{l}\text { İnsanlarda yapılmış kontrollü çalışmalar mevcut; fetal } \\
\text { risk yok. }\end{array}$ \\
\hline B & $\begin{array}{l}\text { İnsanlarda kontrollü çalışma yok; hayvan çalışma- } \\
\text { larında fetal risk yok }\end{array}$ \\
\hline C & $\begin{array}{l}\text { İnsanlar ve hayvanlarda kontrollü çalışmalar yok ya } \\
\text { da sadece hayvanlarda fetotoksik etkisi gösterilmiş; } \\
\text { insanlarda fetal risk kanıtı yok. }\end{array}$ \\
\hline D & $\begin{array}{l}\text { İnsanlarda fetal risk oluşturduğuna dair kanıt mevcut; } \\
\text { yarar-zarar oranına bakılarak kullanılmalı. }\end{array}$ \\
\hline X & $\begin{array}{l}\text { İnsanlarda ve hayvanlarda fetal anomaliye yol açtığı } \\
\text { gösterilmiş; gebe kadında kullanımı yüksek riskli ve } \\
\text { kontrendike. }\end{array}$ \\
\hline * FDA: Amerikan Gıda ve İlaç Dairesi \\
\hline
\end{tabular}

Günümüzde bu sınıflama FDA tarafından değiștirilerek yeni bir kullanıma geçilse de ülkemizde halen kullanılmaktadır. ${ }^{5}$ FDA tarafından yeni yapılan düzenlemede risk özeti, klinik yönetim ve veriler başlıklarının yer almaktadır. Farklı branşlardan hekimler tarafından oluşturulan bu üç bölümlü tanımlamanın, klinik pratikte gebelerde ilaç kullanımı ya da maruziyetinde hekimlere daha iyi yol göstereceği düşünülmektedir (Tablo 2.). Mevcut sınıflandırma günümüzde gerek gebelerde ilaç reçete eden hekimler, gerekse de diğer sağlık çalışanları ve hastalarda ilaçların potansiyel teratojenitesi hakkında en önemli bilgi kaynağıdır. Fakat risk analizi için daha uygun olan yol, gebenin ilaç kullanımı hakkında mevcut teratojenite bilgi servisleri veya konunun uzmanı farmakoloji uzmanlarına yönlendirilmesidir. İlgili birimler ilaç kullanımı ve olası teratojenite riskleri açısından daha doğru ve yol gösterici analizler yapabilmektedir.

Bu çalışmada amacımız, anabilim dalımızda uzun yıllardır verilmekte olan gebelikte ilaç kullanımı danışmanlık hizmeti kapsamında, 2011-2016 yılları arasında tarafımıza başvuran gebelerde bir değerlendirme yapmaktır. Gebelerin kullanmış olduğu ilaçları sınıflandırmak ve sık kulla- 
nılan ilaç ve ilaç gruplarının spesifik ve potansiyel teratojenik etkileri hakkında güncel bilgileri gözden geçirmek, bunun yanı sıra gebelikte ilaç kullanımı hakkında sağlık çalışanlarına yol göstermektir.

\begin{tabular}{|c|c|c|c|}
\hline $\begin{array}{l}\text { Genel Bilgi } \\
\text { Riskler }\end{array}$ & Riskler & $\begin{array}{l}\text { Klinik Değer- } \\
\text { lendirmeler }\end{array}$ & $\begin{array}{l}\text { Arka Plan Ver- } \\
\text { ileri }\end{array}$ \\
\hline $\begin{array}{l}\text { Arka plan } \\
\text { riskine ilişkin } \\
\text { ifadenin dâhil } \\
\text { edilmesi } \\
\text { Bilimsel olarak } \\
\text { kabul edilebilir } \\
\text { hamilelik kayıt- } \\
\text { ları hakkında } \\
\text { iletişim bilgileri }\end{array}$ & $\begin{array}{l}\text { Fetal Risk Özeti } \\
\text { İnsanlardaki } \\
\text { gelişimsel ano- } \\
\text { malilerle ilgili } \\
\text { risk değerlendi- } \\
\text { rilmesi ve diğer } \\
\text { ilgili riskler } \\
\text { İnsan verileriyle } \\
\text { artan risk tespit } \\
\text { edilirse, bir } \\
\text { açılama dahil } \\
\text { edilecektir. } \\
\text { Veriler ilacın } \\
\text { sistemik olarak } \\
\text { absorbe edilme- } \\
\text { diğini gösteri- } \\
\text { yorsa, maternal } \\
\text { kullanımın fetal } \\
\text { maruziyetle so- } \\
\text { nuçlanmasının } \\
\text { beklenmediğine } \\
\text { dair bir açılkla- } \\
\text { ma eklenir. } \\
\text { İlaç sistematik } \\
\text { olarak emil- } \\
\text { diğinde, risk } \\
\text { beyanları veri } \\
\text { türüne (insan } \\
\text { veya hayvan) } \\
\text { göre bölünür ve } \\
\text { ilk önce insan } \\
\text { çalısmalarından } \\
\text { elde edilen bul- } \\
\text { gular sunulur. }\end{array}$ & $\begin{array}{l}\text { Erken gebelikte } \\
\text { yanlışllkla ma- } \\
\text { ruz kalmasına } \\
\text { ilişkin açıklama } \\
\text { veya mevcut } \\
\text { veri yoktur. } \\
\text { Tedavi edilme- } \\
\text { yen hastalıkta } \\
\text { gebe veya fetüs } \\
\text { için bilinen her- } \\
\text { hangi bir riskin } \\
\text { açılaması. } \\
\text { Hamilelik } \\
\text { sırasında doz } \\
\text { ayarlamaları. } \\
\text { Gebelikte ilacın } \\
\text { tek başına veya } \\
\text { artan maternal } \\
\text { yan etkileri. } \\
\text { İlacın doz, } \\
\text { zamanlama ve } \\
\text { tedavi süresinin } \\
\text { gebelikteki } \\
\text { etkileri. } \\
\text { Olası yenidoğan } \\
\text { komplikasyon- } \\
\text { ları ve gerekli } \\
\text { müdahaleler. } \\
\text { İlaç potansiyel } \\
\text { olarak intrapar- } \\
\text { tum sirasında } \\
\text { kullanıllyorsa, } \\
\text { FDA onaylı } \\
\text { bir endikasyon } \\
\text { olmasa bile, } \\
\text { kadın, fetüs } \\
\text { veya yenidoğan } \\
\text { üzerindeki } \\
\text { etkiler hakkında } \\
\text { bilgi dahil edi- } \\
\text { lecektir; doğum } \\
\text { eylemi süresi; } \\
\text { müdahale ih- } \\
\text { tiyacı ve çocuk } \\
\text { üzerindeki uzun } \\
\text { vadeli potansiyel } \\
\text { etkiler dahil } \\
\text { olmak üzere } \\
\text { komplikasyon } \\
\text { riski. }\end{array}$ & $\begin{array}{l}\text { Çalsşma türü, } \\
\text { dozu, süresi, } \\
\text { zamanlaması ve } \\
\text { fetal anomaliler } \\
\text { veya diğer yan } \\
\text { etkiler dâhil } \\
\text { sonuçları dahil } \\
\text { edilmeli. } \\
\text { Önce olumlu ve } \\
\text { olumsuz etkiler, } \\
\text { denek sayısı ve } \\
\text { çalışsma süresi } \\
\text { dâhil olmak } \\
\text { üzere insan veri- } \\
\text { leri sunulur. } \\
\text { Hayvan } \\
\text { çalsssmasıs, dâhil } \\
\text { olan türleri ve } \\
\text { dozların insan } \\
\text { dozu eșdeğer- } \\
\text { lerine yeniden } \\
\text { hesaplanmasını } \\
\text { içerir. }\end{array}$ \\
\hline
\end{tabular}

\section{GEREÇ VE YÖNTEMLER}

Bu çalışma Gülhane Tıp Fakültesi Tıbbi Farmakoloji Anabilim Dalında 2011-2016 yılları arasında gebeliğinin herhangi bir haftasında ilaç kullanım öyküsü ile başvuran gebelerde yürütülmüş olan bir olgu serisidir. Çalışmaya dahil edilen tüm gebeler bir kadın hastalıkları ve doğum uzmanın tarafından gebeliği tıbbi olarak kanıtlanmış ve son adet tarihinden itibaren en az bir ilaç kullanımı öyküsü bulunan ve bu sebepten Tibbi Farmakoloji Anabilim Dalına konsültasyon amacıyla yönlendirilen gebelerdir. İlaç kullanım öyküsü ile başvuran gebeler retrospektif olarak incelendi. Kullanılan ilaçlar hastanın beyanına göre düzenlenmiş konsültasyon raporlarına göre değerlendirildi. Değerlendirilen hastaların kullanmış oldukları ilaçlar ATC (Anatomic Therapeutic Chemical- Yapısal Tedavi Edici Kimyasallar) kodlarına göre gruplandırıldı ve ülkemizde ilaç kısa ürün bilgisinde (KÜB) bulunan FDA sınıflamasına göre sınıflandırıldı. Gebelerin kullandıkları farklı tür ilaç sayıları ve bunların grupları da ayrıca değerlendirildi. Gebelerin demografik bilgileri ve gebeliğin kaçıncı haftasında ilaç kullandıkları da değerlendirmeye alınarak, trimesterlere göre sınıflandırıldı. Bazı ilaçların birden fazla kategoriye girebilmesi nedeniyle, ilaç gebeliğin hangi döneminde kullanıldıysa o döneme özgü FDA sınıflaması belirlendi. Çalışmada gebelerin yaş ortalaması, yaş gruplarına göre dağılımı ve ilaç grupları da değerlendirildi. Hastaların yaşları, son adet tarihleri, ultrasonografik olarak gebelik dönemleri, kullandıkları ilaçlar kliniğimizde kullanılan kayıt sisteminden alındı. Çalışma Helsinki İlkeler Deklerasyonuna uyularak gerçekleştirildi.

\section{BULGULAR}

Çalışmada kliniğimize bu süreçte başvuran toplam 112 gebenin değerlendirilmesi yapıldı. Fakat bunların 2 tanesi emzirmede ilaç danışmanlığı, 1 tanesi de paternal ilaç kullanımı nedeniyle olduğu için çalışmaya dâhil edilmedi. Daha önce belirtildiği üzere çalışmaya dâhil olan tüm gebeler bir kadın hastalıkları ve doğum uzmanı tarafından yönlendirilmiş ve bire bir yüz yüze görüşme gerçekleştirilen gebelerdir. Değerlendirilen gebelerin \%37,61'i 30-34 
yaş aralığı içerisindedir ve ortalama yaş 32'dir (Tablo.2).

\begin{tabular}{|l|c|c|}
\hline \multicolumn{3}{|c|}{ Tablo.2.Çalışmada yer alan gebelerin yaş dağılımı (n: 109) } \\
\hline Gebelerin Yaş Grupları & Gebe Sayısı & $\%$ \\
\hline 20-24 yaş & 5 & 4,58 \\
\hline 25-29 yaş & 30 & 27,52 \\
\hline 30-34 yaş & 41 & 37,61 \\
\hline 35-39 yaş & 22 & 20,18 \\
\hline 40-45 yaş & 11 & 10,09 \\
\hline Toplam & 109 & 100 \\
\hline
\end{tabular}

Gebelerin \%64,22'si birden fazla ilaç kullanmıştır, sadece tek bir ilaç kullanan gebelerin oranı ise \%36'dır (Şekil.1).

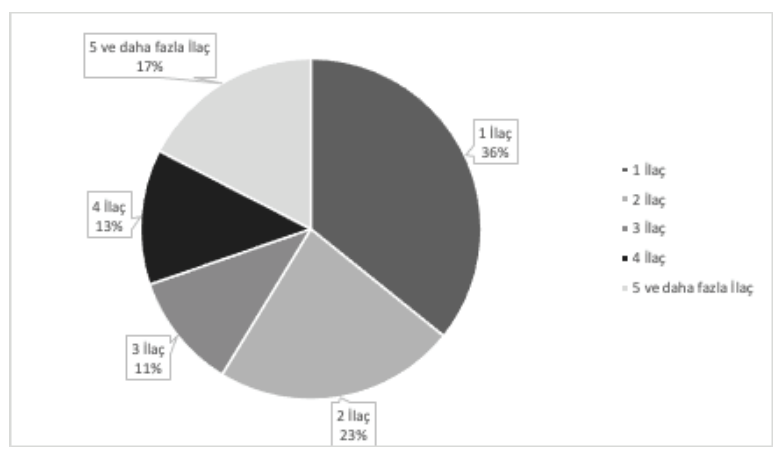

Şekil 1. Çalışmada yer alan gebelerin kullanmış oldukları ilaç sayılarına göre yüzdeleri.

Gebelerin kullanmış olduğu toplam ilaç sayısı 284'tür. En sık kullanılan ilaç grupları ATC sınıflandırılmasına göre; kemoterapötik ilaçlar $37(\% 13,02)$, antiinflamatuvar ve romatizmal ilaçlar $36(\% 12,67)$, solunum sistemi ilaçları 25 $(\% 8,80)$, seks hormonları ve modülatörleri $24(\% 8,45)$ ve gastrointestinal sistem ilaçlarıdır $20(\% 7,04)$ (Tablo.3).
Tablo 3. Çalışmada gebelerin kullanmış olduğu ilaçların gruplara göre dağılımı ve oranı

\begin{tabular}{|l|c|}
\hline İlaç Grubu & Sayısı ve Oranı \\
\hline Kemoterapötik İlaçlar & $37(\% 13,02)$ \\
\hline Anti İnflamatuvar ve Romaztizmal İlaçlar & $36(\% 12,67)$ \\
\hline Solunum Sistemi İlaçları & $25(\% 8,80)$ \\
\hline Seks hormonları ve modülatörleri & $24(\% 8,45)$ \\
\hline Gastrointestinal Sistem İlaçları & $20(\% 7,04)$ \\
\hline Kardiyovasküler Sistem İlaçları & $19(\% 6,69)$ \\
\hline Antidepresan İlaçlar & $19(\% 6,69)$ \\
\hline Sistemik Hormon Preparatları & $19(\% 6,69)$ \\
\hline Analjezikler & $14(\% 4,92)$ \\
\hline Antineoplastik ve İmmunomodülatör İlaçlar & $13(\% 4,57)$ \\
\hline Dermatolojik Preparatlar & $8(\% 2,81)$ \\
\hline Kan ve Kan Yapıcı Preparatlar & $8(\% 2,81)$ \\
\hline Antiparaziter İlaçlar & $7(\% 2,46)$ \\
\hline Antipsikotik İlaçlar & $6(\% 2,14)$ \\
\hline Diyabet İlaçları & $5(\% 1,76)$ \\
\hline Antiepileptikler & $4(\% 1,40)$ \\
\hline Diğer & $20(\% 7,04)$ \\
\hline
\end{tabular}

Gebelerin kullanmış olduğu ilaçların \%49,3'ü FDA sınıflamasina göre 'C' kategorisinde, \%22,5'i 'B' kategorisinde, \%14,4'ü ' $\mathrm{X}$ ' kategorisinde, \%10,2'si 'D' kategorisinde ve \%3,5’i 'A' kategorisinde yer almaktadır (Şekil.2). Özellikle teratojenite açısından riskli olan $\mathrm{D}$ ve $\mathrm{X}$ gruplarındaki ilaçların oranı \%24,6 olarak tespit edilmiştir.

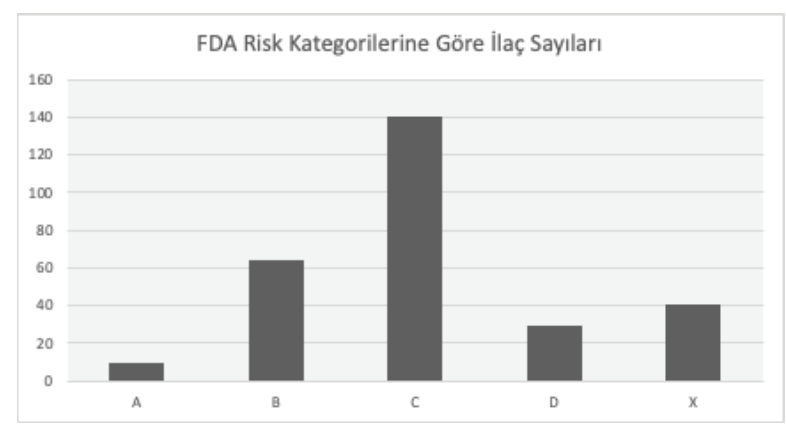

Şekil 2. Gebelerin kullanmış oldukları ilaçların Amerikan Gıda ve İlaç Dairesi (FDA) risk kategorilerine göre dağılımı. 
İlaç kullanımlarının gebelik dönemlerine göre incelendiğinde, ilk trimesterde ilaç kullanan gebelerin oranı \%90,8 olurken, ikinci trimester $\% 7,3$ ve 3 .trimester ise $\% 1,8$ olarak bulunmuştur. Kullanılan ilaçların FDA kategorilerine ve trimesterlere göre dağlımı da Tablo.4’te sunulmuştur.

\begin{tabular}{|c|c|c|c|c|}
\hline \multicolumn{5}{|c|}{$\begin{array}{l}\text { Tablo.4 FDA sınıflamasına göre kullanılan ilaçların trimester- } \\
\text { lere göre dağılımı }(\mathrm{N}=284)\end{array}$} \\
\hline KATEGORİ & $\begin{array}{l}\text { İlaç } \\
\text { Sayısi }\end{array}$ & $\begin{array}{c}1 . \\
\text { Trimester }\end{array}$ & $\begin{array}{c}2 . \\
\text { Trimester }\end{array}$ & $\begin{array}{c}3 . \\
\text { Trimester }\end{array}$ \\
\hline A & 10 & 10 & - & - \\
\hline B & 64 & 60 & 4 & - \\
\hline $\mathrm{C}$ & 140 & 125 & 13 & 2 \\
\hline D & 29 & 27 & 2 & - \\
\hline X & 41 & 35 & 6 & \\
\hline
\end{tabular}

TARTIŞMA

Gebelikte kullanılan ilaçlar gerek fetüs gerekse de anne üzerinde olumsuz etkiler oluşturabileceğinden, üzerinde hassasiyetle durulması gereken bir konudur. Konjenital anomalilerin önlenmesi ve gebelikte ilaç kullanımında potansiyel zararların azaltılabilmesi için doğru ve uygun bir risk analizi yapılması gerekmektedir. Günümüzde bu değerlendirmeyi yapabilecek merkez ve uzman sayısı az olmakla birlikte, hekim ve diğer sağlık çalışanlarının konu hakkındaki bilgileri sınırlıdır. Bu çalışmadan elde edilen veriler doğrultusunda gebelikte sık kullanılan ve maruz kalınan ilaçlar ve bunların potansiyel riskleri hakkında güncel bilgiler tüm sağlık çalışanlarına konu hakkında fikir verme açısından değerlidir.

Her ne kadar FDA gebelik risk kategorileri konu hakkından bir fikir oluştursa da bu bilgiler daha çok ilacın gebelikte kullanılıp kullanılmayacağıyla ilgili olup, ilacı kullanmış olanlarda meydana gelen risk artışını ortaya koymaktan uzaktır.

Çalışmada değerlendirilen gebelerin ortalama yaşı 32 olup, yaklaşık \%38’i 30-34 yaş aralığındadır. Ülkemizde bu periyodda annenin doğumdaki ortalama yaşı 27,4 ile 28,6 arasında olduğu göz önüne alınırsa bize başvuran gebelerin yaşlarının ortalamadan yüksek olduğu, bunun nedeninin de kliniğimize başvuran gebelerin sosyo-ekonomik durumundan kaynaklandığı düşünülebilir. ${ }^{6}$ Ayrıca gebelerin yaklaşık \%65'inin birden fazla ilaç kullandığı görülmüş olup ortalama ilaç kullanım sayısı 2,60'dır. Birden fazla ilaç kullanan gebelerdeki ilaç türlerine baktığımızda, bunların sıklıkla gebedeki ilaç kullanımını gerektiren klinik durumdan kaynaklandığg görülmektedir. Birlikte kullanılan ilaçlar her hangi bir sınıflandırmaya uymamakla birlikte tamamen gebedeki klinik durumu düzeltmeye yönelik tedavileri içermektedir. Bu durum hem risk artışı açısından hem de polifarmasi ve ilaç etkileşmeleri açısından da önemlidir. Yapılan çalışmalar benzer şekilde kadınların hamilelik sırasında ortalama 2.6 ilaç kullandığını ifade etmektedir ve bizim sonuçlarımızla benzerlik göstermektedir. $^{3}$

Gebelerin ilaç kullanım periyotları incelendiğinde büyük çoğunluğunun $(\% 90,8)$ gebeliğin ilk trimesterinde olduğu görülmektedir ve daha önceki çalışmalara da uygunluk göstermektedir. Bu kullanımların büyük çoğunluğu, kadınların hamile olduklarını fark etmeden önce, hamileliğin ilk haftalarında aldıkları ilaçlardan kaynaklanmaktadır. ${ }^{7}$ Bizim çalışmamızda da yüz yüze yaptığımız görüşmelerde bu tip bir kullanımın ön planda olduğunu desteklemektedir, öyle ki ilk trimester içinde kullanılan ilaçların \%53,2'si ilk 6 haftalık periyod içerisinde kalmaktadır. İkinci ve üçüncü trimesterde ilaç kullanımları sırasıyla \% 7,3 ve \%1,8'dir. Orandaki bu düşüklük gerek gebelerin bu konuda daha bilinçli olması gerekse de gebeliğin bu periyodundaki ilaç kullanımlarının genellikle mutlak gereklilik arz etmesinden kaynaklanıyor olabilir.

Çalışmamızda en çok kullanılan ilaç grubunun kemoterapötik ilaçlar olduğu görüldü $(\% 13,02)$. Ülkemizde en çok reçete edilen ilaç gruplarının başında kemoterapötikler yer aldığından dolayı bu sonucun beklenebilir olduğu söylenebilir. Gebelikte üriner sistem ve üst solunum yolu enfeksiyonları gibi sık görülen enfeksiyonların tedavisin- 
de kullanılan, beta-laktamlar, vankomisin, nitrofurantoin, metronidazol, klindamisin ve fosfomisin gibi antibiyotiklerin genellikle güvenli ve etkili olduğu düşünülmektedir. ${ }^{8}$ Fakat aminoglikozidler, tetrasiklinler ve florokinolonların gebelerde kullanımı sakıncalıdır. Aminoglikozitler plasentadan geçer ve özellikle hamileliğin ilk trimesterinde kullanımı fetal toksisiteye neden olabilir. ${ }^{9}$ Florokinolonlar her ne kadar ' $\mathrm{C}$ ' kategorisinde yer alsalar da fetüste böbrek toksisitesi, kardiyak defektler ve santral sinir sistemi toksisitesi ile ilişkili olabileceği belirtilmektedir. ${ }^{10,11}$ Ayrıca deney hayvanlarında iskelet ve kıkırdak anomalilerine de neden olabilmektedir. ${ }^{9}$ Gebelikte kullanımı sakıncalı olan bir diğer antibiyotik grubu da tetrasiklinlerdir. Çocukluk çağında da kullanılmayan tetrasiklinler, özellikle 2. trimesterde plasentadan geçerek fetüste kalsiyumu bağlamak suretiyle kemik ve dişlerde kalıcı renk değişikliğine neden olabilir. ${ }^{9}$ Özellikle gebeliğin 5.haftasından itibaren tetrasiklin kullanımı kontraendikedir. Tüm bu spesifik teratojenik etkilerin yanı sıra gebelikte glomerüler filtrasyon hızında, toplam vücut hacminde ve kalp debisine artış gibi değişikliklerden dolayı, antibiyotik kullanımında daha dikkatli olunması ve doz ayarlaması gerekebilir. ${ }^{8}$

Diğer sık kullanılan ilaç grubu olan non-steroidal anti-inflamatuvar (NSAI) ve romatizmal ilaçlar yine gebelik dışında da sık reçete edilen ilaçlardandır. Bu ilaçlar gebelerde ateş, ağrı ve inflamasyonu tedavi etmek için sıklıkla kullanılırlar. Bunun yanı sıra soğuk algınlığı tedavisinde kullanılan anti-gribal ilaçların muhteviyatında da bulunabilirler. Düşük ve malformasyon riskinin artması, erken gebelikte NSAI ilaç kullanımı ile ilişkilidir. Yanı sıra gebeliğin 30. haftasından sonra NSAI ilaç kullanımı fetal duktus arteriyozus erken kapanması ve oligohidramnios riski ile de ilişkilidir. Ayrıca prenatal NSAI ilaç maruziyeti sonrasında beyin, böbrek, akciğer, iskelet, gastrointestinal ve kardiyovasküler sistemleri de etkileyen fetal ve neonatal advers etkiler de bildirilmiştir. ${ }^{12}$ Özellikle diklofenak kullanımı ile gebelik ve doğum sonrası maternal vajinal kanama ilişkilendirilmiştir. ${ }^{13} \mathrm{Bu}$ olumsuz etkilerden dolayı NSAI ilaçlar mutlak endike olmadıkları durumlarda, özellikle son trimesterde, kullanılmamalıdır. Ağrı kesici ve ateş düşürücü olarak daha güvenli olan parasetamol tercih edilmelidir.

Çalışmamızda gebelerde sık kullanılan bir başka ilaç grubu ' $\mathrm{X}$ ' kategorisinde yer alan seks hormon preparatlar1dır. Bu gruba dahil olan kombine oral kontraseptif ilaçlar sıklıkla gebeliğin farkına varılmadığı periyodda gebeliği önlemek amacıyla kullanılırken, progesteron preparatları ise sekonder amenore tedavisinde menstürasyonu indüklemek amacıyla kullanılmaktadır. Özellikle adet düzensizliği olan gebelerin adet görmemesini gebeliğe bağlamayıp bu amaçla medroksiprogesteron asetat ve noretisteron gibi ajanları kullanması sıklıkla karşılaştığımız bir durumdur. Her ne kadar bu grup ilaçlar gebelikte mutlak kullanılmaması gereken ilaçlar olsa da yapılan çalışmalarda bu tarz kullanımların teratojenite riskinde bir artış oluşturmadığg gösterilmiştir. ${ }^{14}$ Sadece bazı yayınlarda hipospadias riskinde artışa neden olabileceği belirtilmektedir fakat kontrasepsiyon amacıyla progestin kulanımı artmış risk ile ilişkili bulunmamıştır. ${ }^{15}$ Özellikle konu hakkında yeterli bilgisi olamayan hekimler ' $\mathrm{X}$ ' grubu bu tür ilaçların kullanımı sonrası, yanlış potansiyel teratojenik etki nedeniyle gebeliğin sonlandırılmasını tavsiye edebilmektedir.

Solunum sistemi ilaçları da normal popülasyonda olduğu gibi gebelerde de sık kullanılan bir ilaç grubudur. Soğuk algınlığı için kullanılan kombine preparatlar içerisindeki etken maddeler ele alındığında kısa süreli kullanımda genellikle ciddi bir teratojenite riski taşımamaktadır. ${ }^{16}$ Fakat kullanımı gereken hallerde analjezik içeriği ibuprofen ve asetilsalisilik asit yerine parasetamol olanlar tercih edilmelidir. Bu grupta yer alan antihistaminik ilaçların yine gebelikte önemli teratojenik etkileri yoktur. Yapılan geniş çaplı bir meta analiz sonucu antihistaminikler artmış majör malformasyon riski veya diğer olumsuz fetal sonuçlar ile ilişkili bulunmamıştır. ${ }^{17}$ Astım ilaçları içerisinde yer alan steroidler yapılan bazı vaka kontrol çalışmalarının meta-analizinde orofasiyal yarıklarla ilişkilendirilse de, ancak bu risk artışı son zamanlarda yapılan büyük bir kohort çalış- 
mada doğrulanmamıştır. ${ }^{18-19} \mathrm{Bu}$ olası riskler, ciddi astım akut alevlenmesi sonucu oluşabilecek maternal veya fetal mortaliteyi de içeren potansiyel risklerinden daha az olacağından, hamilelik sırasında şiddetli astımın tedavisi için oral kortikosteroidler kullanılabilmektedir. ${ }^{20}$ İnhale bronkodilatörler bazı çalışmalarda çeşitli anomalilerle ilişkilendirilmiştir. ${ }^{21}$ Erken gebelikte astım ilaçları kullanan kadınlarda doğan bebeklerde konjenital malformasyon riski çok az artmaktadır. Fakat bu artışın astım hastalığına ya da kullanılan ilaçlara bağlı olup olmadığı belirsizdir. ${ }^{22}$

Antidepresan ilaçlar gebelikte kullanımları ile ilgili oldukça çelişkili durumlar olan bir ilaç grubudur. Klinik depresyon gebelikte \%10-15 sıklıkla ortaya çıkmaktadır. ${ }^{23}$ Bizim çalışmamızda ise ilaç kullanan gebelerin yaklaşık \%7'si gebeliğinin en az bir kısmında antidepresan kullandığını ifade etmiştir. Erken dönem gebelikte seçici serotonin geri alım inhibitörleri (SSRI), özellikle sertralin ve sitalopram kullanan kadınların çocuklarında septal kalp defektlerinin prevalansının arttığını gösteren çalışmalar yayınlanmıştır. ${ }^{24}$ Fakat daha sonra yayınlanan bazı editoryal yazılarda belirtildiği gibi, bunun "ciddi bir endişe mi yoksa boşuna bir telaş mı" olduğu konusunda ciddi tartışmalar devam etmektedir. ${ }^{25}$ Sonrasında büyük bir popülasyonda yapılan kohort çalışmasının sonuçları, SSRI'ların kardiyak malformasyon riskinde önemli bir artış oluşturmadığını göstermektedir. ${ }^{26}$ Yakın zamanda yayınlanan bir sistematik derlemede ise gebelikte antidepresan kullanımının düşük doğum ağırlığı, nörogelişimsel ve nörodavranışsal sonuçlar üzerindeki zararlı etkisini gösteren kanıtların yetersiz olduğu ve konu hakkında daha kapsamlı çalışmaların yapılmasına ihtiyaç duyulduğu belirtilmiştir. ${ }^{27} \mathrm{Bu}$ çalışmaların en önemli kısıtlıklarından birisi de risk artışının karşılaştırıldığı gruplarda, antidepresan kullanan gebelerle depresyon tanısı alıp ilaç kullanmayanların değil, normal gebelerin karşılaştırılması olabilir.

Sonuç olarak çalışmamızdan elde ettiğimiz veriler, gebe kadınların bilerek ya da bilmeyerek kullanmış olduğu ilaçların yaklaşık \%75’inin, insanlarda gebelik esnasında kullanım güvenliliği tam olarak belli olmayan ve/veya insanlar ve hayvanlarda potansiyel teratojenik risk taşıyan ilaçlar olduğunu göstermektedir. Bu sebepten dolayı gerek ilaç reçete eden hekimlerin gerekse ilacı kullanan doğurganlık çağındaki kadınların, kullanım öncesi mutlaka gebe olup olmadığının sorgulanması gerekmektedir. Gebelik durumunda ise ilaç seçiminin mümkün olan en az risk taşıyan gruptan yapılması önem arz etmektedir. İlaç maruziyeti durumunda ise, mümkünse konunun uzmanı bir farmakolog veya teratojenite danışma servisi tarafından; kullanılan ilaç, kullanım süresi, kullanım dozu, kullanım periyodu ve ilave riskler gibi tüm parametreler göz önüne alınarak risk değerlendirilmesi yapılmalıdır. Bu değerlendirmenin 1şığında gebeliğin sürdürülmesi, olası sonuçlar açısından gebeliğin nasıl takip edileceği konularında gebenin bilgilendirilmesi de oldukça önem taşımaktadır. Konuyla ilgili bir başka husus ise, mevcut risk değerlendirilmesinin yapılmasına olanak veren FDA sınıflanmasının yeterli güvenliğe sahip olmayışıdır. ${ }^{5}$ Dolayısıyla riski ve güvenliği daha iyi ortaya koyabilecek yeni bir sınıflandırma yapılmasına ihtiyaç duyulmaktadır.

\section{Bu çalışma; Helsinki Deklerasyonuna uyularak yapıl-} miştır. 


\section{Kaynaklar}

1. Andrade SE, Gurwitz JH, Davis RL, Chan KA, Finkelstein JA, Fortman K, et al. Prescription drug use in pregnancy. Am J Obstet Gynaecol. 2004;191:398-407. doi: 10.1016/j. ajog.2004.04.025

2. Bakker MK, Jentink J, Vroom F, Van Den Berg PB, De Walle HEK, De Jong-Van Den Berg LTW. Drug Prescription Patterns Before, During and After Pregnancy for Chronic, Occasional and Pregnancy-Related Drugs in the Netherlands. BJOG 2006;113(5):559-68. doi: 10.1111/j.1471-0528.2006.00927.x

3. Mitchell AA, Gilboa SM, Werler MM, Kelley KE, Louik C, Hernández-Díaz S; National Birth Defects Prevention Study. Medication use during pregnancy, with particular focus on prescription drugs: 1976-2008. Am J Obstet Gynecol. 2011;205(1):51.e1-8. doi: 10.1016/j. ajog.2011.02.029

4. Lupattelli A, Spigset O, Twigg MJ, Zagorodnikova K, Mårdby AC, Moretti ME, et al. Medication use in pregnancy: a cross-sectional, multinational web-based study. BMJ Open. 2014;17:4(2):e004365. doi: 10.1136/bmjopen-2013-004365

5. Kaplan YC, Can H, Demir Ö, Karadaş B, Yllmaz İ, Temiz TK. İlaçların gebelikte kullanımlarına dair risk iletişiminde yeni dönem: FDA gebelik risk kategorileri değişiyor. Türkiye Aile Hekimliği Dergisi 2014;18(4):195-8. doi:10.15511/tahd.14.04195

6. Türkiye İstatistik Kurumu (TÜIK), http://www.tuik.gov.tr/PreHaberBultenleri. do?id=30710, Erişim Tarihi: 22/06/2020.

7. Sachdeva P, Patel BG, Patel BK. Drug use in pregnancy; a point to ponder!. Indian J Pharm Sci. 2009;71(1):1-7. doi:10.4103/0250-474X.51941

8. Bookstaver PB, Bland CM, Griffin B, Stover KR, Eiland LS, McLaughlin M. A review of antibiotic use in pregnancy. Pharmacotherapy. 2015;35(11):1052-62. doi:10.1002/phar.1649

9. Briggs GG, Freeman RK. Drugs in Pregnancy and Lactation: A Reference Guide to Fetal and Neonatal Risk.11th ed. Philadelphia: Lippincott Williams \& Wilkins, 2017.

10. Crider KS, Cleves MA, Reefhuis J, Berry RJ, Hobbs CA, Hu DJ. Antibacterial medication use during pregnancy and risk of birth defects: National Birth Defects Prevention Study. Arch Pediatr Adolesc Med 2009;11 978- 85. doi: 10.1001/archpediatrics.2009.188

11. Guinto VT, De Guia B, Festin MR, Dowswell T. Different antibiotic regimens for treating asymptomatic bacteriuria in pregnancy. Cochrane Database Syst Rev 2010; 9: CD007855. doi: 10.1002/14651858.CD007855.pub2

12. Antonucci R, ZaffanelloM, Puxeddu E, Porcella A, Cuzzolin L, Pilloni MD, et al. Use of Non-steroidal Anti-inflammatory Drugs in Pregnancy: Impact on the Fetus and Newbor. Current Drug Metabolism (2012) 13: 474-90. doi:10.2174/138920012800166607

13. Nezvalová-Henriksen $K$, Spigset $O$, Nordeng $H$. Effects of ibuprofen, diclofenac, naproxen, and piroxicam on the course of pregnancy and pregnancy outcome: a prospective cohort study. BJOG. 2013;120(8):948-59. doi:10.1111/1471-0528.12192

14. Practice Committee of American Society for Reproductive Medicine in collaboration with Society for Reproductive Endocrinology and Infertility. Progesterone Supplementation During the Luteal Phase and in Early Pregnancy in the Treatment of Infertility: An Educational Bulletin Fertil Steril. 2008;90(5 Suppl):S150-3. doi: 10.1016/j.fertnstert.2008.08.064
15. Carmichael SL, Shaw GM, Laurent C, Croughan MS, Olney RS, Lammer EJ. Maternal Progestin Intake and Risk of Hypospadias. Arch Pediatr Adolesc Med. 2005;159(10):957-62. doi: 10.1001/archpedi.159.10.957

16. Erebara A, Bozzo P, Einarson A, Koren G. Treating the common cold during pregnancy. Can Fam Physician. 2008;54(5):687-9

17. Etwel F, Faught LH, Rieder MJ, Koren G. The Risk of Adverse Pregnancy Outcome After First Trimester Exposure to H1 Antihistamines: A Systematic Review and Meta-Analysis. Drug Saf. 2017;40(2):121-32. doi: 10.1007/s40264-016-0479-9

18. Park-Wyllie L, Mazzotta P, Pastuszak A, Moretti ME, Beique L, Hunnisett L, et al. Birth defects after maternal exposure to corticosteroids: Prospective cohort study and meta-analysis of epidemiologic studies. Teratology. 2000;62:385-92. Doi: 10.1002/1096-9926(200012)62:6<385::AID-TERA5>3.0.CO;2-Z

19. Hyiid A, Molgaard-Nielesen D. Corticosteroid use during pregnancy and the risk of orofacial clefts. CMAJ. 2011;183:796-804. doi: 10.1503/cmaj.101063

20. Namazy J, M Schatz. The Treatment of Allergic Respiratory Disease During Pregnancy. J Investig Allergol Clin Immunol. 2016;26(1):1-7. doi: 10.18176/jiaci.0001

21. Lin S, Munsie JP, Herdt-Losavio ML, Druschel CM, Campbell K, Browneet ML, et al. Maternal asthma medication use and the risk of selected birth defects. Pediatrics. 2012;129(2):e317-e324. doi:10.1542/peds.2010-2660

22. 22. Källén B, Olausson PO. Use of Anti-Asthmatic Drugs During Pregnancy. 3.Congenital Malformations in the Infants. Eur J Clin Pharmacol. 2007;63(4):383-8. doi:10.1007/s00228006-0259- $z$

23. Evans J, Heron J, Francomb H, Oke S, Golding J. Cohort study of depressed mood during pregnancy and after childbirth. BMJ. 2001;323(7307):257-60. doi: 10.1136/bmj.323.7307.257

24. Pedersen LH, Henriksen TB, Vestergaard M, Olsen J, Bech BH. Selective serotonin reuptake inhibitors in pregnancy and congenital malformations: population based cohort study. BMJ. 2009;339:b3569. doi:10.1136/bmi.b3569

25. Greene MF. Teratogenicity of SSRIs--serious concern or much ado about little. N Engl J Med. 2007;356(26):2732-3. doi:10.1056/NEJMe078079

26. Huybrechts KF, Palmsten K, Avorn J, Cohen LS, Holmes LB, Franklin JM, et al. Antidepressant use in pregnancy and the risk of cardiac defects. N Engl J Med. 2014;370(25):2397-407. doi:10.1056/NEJMoa1312828

27. Prady SL, Hanlon I, Fraser LK, Mikocka-Walus A. A systematic review of maternal antidepressant use in pregnancy and short-and long-term offspring's outcomes. Arch Womens Ment Health. 2018;21(2):127-40. doi:10.1007/s00737-017-0780-3 